
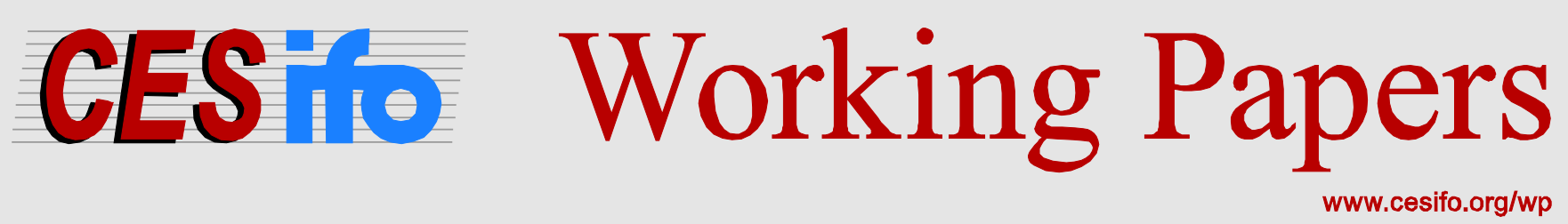

\title{
The European Central Bank’s QE: A New Hope
}

\author{
Tomasz Wieladek \\ Antonio Garcia Pascual
}

\author{
CESIFO WORKING PAPER NO. 5946 \\ CATEgory 7: MONETARY POLICY AND INTERNATIONAL FINANCE \\ JUNE 2016
}

An electronic version of the paper may be downloaded

- from the SSRN website:

- from the RePEc website:

- from the CESifo website: wWw.SSRN.com

Www.RePEc.org

www.CESifo-group.org/wp 


\title{
The European Central Bank’s QE: A New Hope
}

\begin{abstract}
We examine the impact of the ECB's QE on Euro Area real GDP and core CPI with a Bayesian VAR, estimated on monthly data from 2012M6 to 2016M4. We assess the total impact via a counter-factual exercise, country-by-country and through alternative transmission channels. QE anouncement shocks are identified with four different identification schemes as in Weale and Wieladek (2016). We find that in absence of the first round of ECB QE, real GDP and core CPI would have been $1.3 \%$ and $0.9 \%$ lower, respectively. The effect is roughly $2 / 3$ times smaller than in the UK/US. Impulse response analysis suggests that the policy is transmitted via the portfolio rebalancing, the signalling, credit easing and exchange rate channels. Spanish real GDP benefited the most and Italian the least.
\end{abstract}

JEL-Codes: E500, E510, E520.

Keywords: ECB unconventional monetary policy, transmission mechanism.

Tomasz Wieladek

Barclays Research

London / United Kingdom

tomasz.wieladek@barclays.com
Antonio Garcia Pascual

Barclays Research

London / United Kingdom

antonio.garciapascual@barclays.com 


\section{Introduction}

Unlike the Bank of England, the Bank of Japan and the Federal Reserve, the European Central Bank announced purchases of sovereign debt as means to stimulate aggregate demand only recently. There are a number of studies that have examined the impact of this policy for the UK and the US, both with Bayesian VAR (BVAR) methods and more structural econometric models. ${ }^{1}$ While Altavilla, Carboni and Motto (2015) provide the first financial market event study, to our knowledge this is the first study that examines the macroeconomic effects of this policy for the Euro Area.

We use a BVAR framework to examine the impact of ECB QE on the Euro Area real GDP and core CPI in a number of ways. First, we assess the total impact of the policy by comparing data outturns to a counterfactual where it is not announced. This is the approach taken by Baumeister and Benati (2013) for the UK and the US and Kapetanios, Mumtaz, Theodoris and Stevens (2012) for the UK. As a next step, we follow the approach presented in Weale and Wieladek (2016), and examine the impact in a structural VAR framework. Their approach has a number of advantages: By estimating our model on monthly data over the period when the policy was actually deployed, the results are less susceptible to the Lucas critique. All of four identification schemes introduced in their work leave the response of output and prices unrestricted. Whether or not real GDP and core CPI react to ECB QE is therefore decided by the data. This is especially important in the case of QE as economic theory does not concur on how this policy should be identified, and this is likely to remain the state of affairs for some time. Reporting results across four different identification schemes therefore helps to adress identification uncertainty. Finally, following their approach allows us to directly compare the quantitative impact of the ECB's QE to the strength and impact of this policy in the UK and the US, presented in Weale and Wieladek (2016).

Economic theory suggests that QE might affect the real economy via a number of mechanisms: The most frequently cited is the so-called portfolio balance channel (Vayanos and Villa, 2009). This relies on the presence of investors with a preferred habitat for a given maturity in the government bond market. If this is the case, purchases of long-term government debt reduce yields at the corresponding maturity, through their impact on term premia. Eggertson and Woodford (2003) and

\footnotetext{
${ }^{1}$ See for example Chung et al. (2012) and Kapetanios et al. (2012) for studies that examine the impact of QE in the US and the UK, with structural econometric frameworks and Bayesian VARs, respectively.
} 
Bernanke, Reinhart and Sack(2004) also argue that QE can signal that the short-term interest rate will stay lower for longer. A third possible transmission mechanism, proposed by Weale and Wieladek (2016) is that asset purchases reduce uncertainty about financial markets and the economy more generally. The rise in banking system liquidity associated with the issuance of reserves can also push interbank rates at various maturies closer to the reserve deposit rate, and so long this is passed on, stimulate the macroeconomy through the credit easing channel of QE. Finally, the exchange rate channel of QE implies that the nominal exchange rate could depreciate, with an improvement in the trade balance. All of these transmission mechanisms could play a role in helping QE to stimulate aggregate demand.

While our modeling framework does not allow us to explicitly quantify the contribution of each channel, we can at least discriminate among them by including relevant variables in the VAR one-byone. If the portfolio balance mechanism is behind the reduction in government bond yields, one should observe a relatively greater reaction of yields at longer maturities. The credit easing channel implies that interbank rates should decline to the reserve deposit rate. The signalling channel implies that the spread of the future rate to the corresponding interbank rate should decline as well. Weale and Wieladek (2016) argue that the uncertainty channel implies that the VIX and a weighted average of implied interest rate futures' volatilities (MOVE) should decline in response to QE announcements. Finally, the exchange rate should depreciate in response to QE if the exchange rate channel operates.

Our conditional forecast exercise shows that, compared to a world without ECB QE, the levels of EA real GDP and core CPI are approximately $1.3 \%$ and $0.9 \%$ higher, respectively. Compared to previous BVAR estimates of these policies in the UK and the US obtained with either the term spread shock approach in Baumeister and Benati (2013) and Kapetanios et al (2012) or the asset purchase announcement approach in Weale and Wieladek (2016), our impulse response analsysis suggests that the effect of ECB QE is roughly half as powerful as in the UK and one-third as powerful as in the US.

In terms of the transmission mechanism, we find evidene for the portfolio rebalancing channel. Our conditional forecasting exercise suggests that long-term interest rates fell by approximately 160bps in response to this policy. The euro area's overnight OIS rate, EONIA, and Euribor rates with longer maturies also react negatively to this policy. SME and household new lending rates decline as well. Together this supports the presence of a credit easing channel. There is 
also some evidence for the signalling channel. But the large response of long-term yields is consistent with the idea that the portfolio balance channel is perhaps the strongest. Unlike, in the US and the UK, the 'reduction in uncertainty' channel does not seem to be relevant.

Finally, we examine to which extent this policy affected different countries. Our results here suggest that Spanish real GDP rises four times more than Italian real GDP in response to QE. This could reflect the difference in policies towards structural and banking sector reform that these two countries have taken. The impact on real GDP in Portugal is larger than Italy's but smaller than Spain's, which supports this assertion given that the Portugese authorites have undertaken significant structural reforms, but the banking sector is still fragile. If this is correct then Italy can only expect limited benefit from future QE, unless structural and banking sector reforms are implemented. While the overall impact of QE on inflation is very moderate, we find that the biggest core CPI inflation impact is in Germany, with the lowest in Spain. This is consistent with the idea that QE should have a larger impact on prices in countries were spare capacity is limited than in those were resources are still abundant.

An important caveat of our study is that the TLTRO was announced close to QE, and cuts to the deposit rate into negative territory were implemented at the same time. Due to this coincidence of policies, it is practically impossible to separate all of their individual effects empirically. Our impact estimate is therefore an upper bound of the ECB's QE policy and will likely reflect the other policies as well. Yet given that this is the first study of its kind, we nevertheless find the results relevant and informative.

The remainder of this paper proceeds as follows. Section two explains our model and discusses the details of our identification schemes. Section three presents the results and section four concludes.

\section{Methodology and data}

We use the following VAR model estimated on monthly data:

$$
Y_{t}=\alpha_{c}+\sum_{k=1}^{L} A_{k} Y_{t-k}+e_{t} \quad e_{t} \sim N(0, \Sigma)
$$

where $\boldsymbol{Y}_{\boldsymbol{t}}$ is a vector of the following endogenous variables: the announcement of asset purchases divided by nominal GDP; the log of CPI; the log of real GDP; the yield on the 10-year government bond and the $\log$ of real equity prices at time $\boldsymbol{t}$. $\boldsymbol{A}_{\boldsymbol{k}}$ is the array of coefficients associated with the 
corresponding lagged vector of variables for lag $\boldsymbol{k} . \boldsymbol{e}_{\boldsymbol{t}}$ is a vector of residuals at time $\boldsymbol{t}$. This is assumed to be normally distributed with variance-covariance matrix $\boldsymbol{\Sigma}$. When the time-series dimension is small, estimates of $\boldsymbol{A}_{\boldsymbol{k}}$ are likely to be imprecise. Previous work has addressed this problem by relying on Bayesian methods of inference and imposing a Litterman (1986), or time-varying parameter, prior. But there is always the risk that tight priors dominate information from the data. Our approach avoids this problem. We use a non-informative normal inverse-Wishart prior, following the approach in Uhlig (2005). We assume a lag length, L, of two throughout. ${ }^{2}$

\subsection{Identification}

The challenge for structural VAR models is to disentangle orthogonal, structural economic shocks, $\varepsilon_{c, t}$, from the correlated reduced form shocks $e_{c, t}$. This is typically achieved using a matrix $C_{0}$, such that $C_{0} e_{c, t}=\varepsilon_{c, t}$. We use four ways of inferring $C_{0}$, zero restrictions, sign restrictions, a combination of zero and sign restrictions, and finally sign variance decomposition restrictions. All of these identification schemes are described in Figure 1.

Identification scheme I uses a lower-triangular scheme, with asset purchases ordered after real GDP and prices, but before all of the other variables. The identifying assumptions are therefore that output and prices react with a lag and that aside from responding to these two, asset purchases do not react to any other variable upon impact.

VAR identification schemes that employ timing exclusion restrictions have been criticised in recent years, on the grounds that such restrictions do not naturally emerge from DSGE models. Canova and De Nicolo (2002), Faust and Rogers (2003) and Uhlig (2005) have therefore proposed identifying shocks by means of the implied signs of the impulse responses that they produce. Clearly, for identification restrictions of this type to be valid, they need to be strongly supported by economic theory. In the presence of financial frictions, such as imperfect substitutability between long and short bonds (Harrison, 2012) or preferred habitat investors (Vayanos and Villa, 2009), economic theory suggests that a rise in asset purchases will lead to a fall in the interest rate on long-term bonds by reducing term premia. But even in the absence of frictions, announcements of asset purchases can

${ }^{2}$ Ex ante lag length tests such as the Hannan-Quinn or BIC criterion suggest a lag length of 2. 
signal that the short-term interest rate is going to stay lower for longer (Eggertson and Woodford, 2003), depressing the long rate. Second, lower yields on longer maturity bonds are likely to lead to some reallocation towards other assets, such as equities, generating a rise in real equity prices. Thus, our definition of an asset purchase shock is that it leads to lower long-term rates and higher equity prices.

The other shocks that we identify are aggregate demand shock, which would typically lead to a rise in prices and output. The rise in prices, together with the fact that firms may require greater finance for production, is likely to lead to a non-negative response of the long-term interest rate. The rise in demand would also lead to higher expected profits and, thus, a rise in real equity prices. The sign restrictions used to identify an aggregate supply shock are identical, other than assuming that prices fall rather than rise. This identification scheme, referred to as scheme II throughout the paper, is summarised in Figure 1. Unless otherwise noted, all sign restrictions are imposed upon impact and one month thereafter with the exception of asset purchase announcements, where the sign restriction is imposed upon impact and for five months thereafter (we follow a similar strategy in identification schemes III and IV).

In identification scheme II, the assumption is that asset purchases affect the real economy via portfolio rebalancing from long-term government bonds into equities, to distinguish them from aggregate supply and aggregate demand shocks. But a priori, it is not clear to what extent the mechanisms that are required for asset purchases to affect the yield on long-term government debt operate in reality. More importantly, to distinguish asset purchase from aggregate supply shocks, it is necessary to assume that long-term interest rates rise in response to an aggregate supply shock. We nevertheless drop this restriction in identification scheme III.

This is possible, as long as one is willing to make the assumption that asset purchases do not react contemporaneously to aggregate demand and aggregate supply shocks. In that case, the restriction on real equity prices is sufficient to distinguish these shocks from asset purchases. Given that monetary policymakers do not observe aggregate demand or supply shocks within a month, the assumption of a zero contemporaneous reaction of asset purchases to aggregate demand and supply shocks is realistic. An additional advantage is that this allows us to identify a fourth shock, namely a 
rise in uncertainty/risk premia. This is identified as a decline in real equity prices, to which the monetary policy authority reacts with a rise in asset purchases, perhaps as a result of a coincident financial crisis. Unlike demand and supply, these types of shocks can be observed in real time. This identification scheme is referred to as identification scheme III throughout.

FIGURE 1

Identification Schemes

\begin{tabular}{|c|c|c|c|c|c|}
\hline & $\begin{array}{c}p \\
\text { Log } \\
\text { CPI }\end{array}$ & $\begin{array}{c}y \\
\text { Log real } \\
\text { GDP }\end{array}$ & $\begin{array}{c}\text { AP } \\
\text { Asset } \\
\text { Purchases }\end{array}$ & $\begin{array}{c}i_{t} \\
\text { Long Interest } \\
\text { Rate }\end{array}$ & $\begin{array}{c}s p_{t} \\
\text { Log Real Equity Price }\end{array}$ \\
\hline \multicolumn{6}{|c|}{ Identification Scheme I } \\
\hline $\log$ CPI & 1 & 0 & 0 & 0 & 0 \\
\hline Log real GDP & & 1 & 0 & 0 & 0 \\
\hline Asset Purchases & & & 1 & 0 & 0 \\
\hline Long Interest Rate & & & & 1 & 0 \\
\hline Log Real Equity Price & & & & & 1 \\
\hline \multicolumn{6}{|c|}{ Identification Scheme II } \\
\hline Supply Shock & - & + & & + & + \\
\hline Demand Shock & + & + & & + & + \\
\hline Asset Purchase Shock & & & + & - & + \\
\hline \multicolumn{6}{|c|}{ Identification Scheme III } \\
\hline Supply Shock & - & + & 0 & & \\
\hline Demand Shock & + & + & 0 & & \\
\hline Asset Purchase Shock & & & + & & + \\
\hline Uncertainty Shock & & & + & & - \\
\hline \multicolumn{6}{|c|}{ Identification Scheme IV } \\
\hline & & & & \multicolumn{2}{|c|}{ Variance Decomposition Restrictions } \\
\hline Supply Shock & - & + & & $\frac{\operatorname{Var}}{\operatorname{Var}(A s S}$ & $<M A X\left(\frac{\operatorname{Var}(\text { Shock })}{\operatorname{Var}(\text { Asset Purchases })}\right)$ \\
\hline Demand Shock & + & + & & $\frac{\operatorname{Var}}{\operatorname{Var}(A s s}$ & $<M A X\left(\frac{\operatorname{Var}(\text { Shock })}{\operatorname{Var}(\text { Asset Purchases })}\right)$ \\
\hline Asset Purchase Shock & & & + & $\frac{\operatorname{Var}}{\operatorname{Var}(A s s}$ & $=\operatorname{MAX}\left(\frac{\operatorname{Var}(\text { Shock })}{\operatorname{Var}(\text { Asset Purchases })}\right)$ \\
\hline
\end{tabular}

Note: The table shows the restrictions imposed by each of the four identification schemes. Grey shading indicates that the response of the variable (in the column) to the shock (in the row) is unrestricted, + indicates that it is restricted to be non-negative, 1 to be 1,0 to be zero and - to be non-positive. Source: Weale and Wieladek (2016). 
At present, the theory underlying asset purchases is not sufficiently well understood to devise an identification scheme that would allow us to identify asset purchase announcement shocks perfectly. It is for this reason that we sequentially relax the strongest identification restrictions from the first scheme to the last. Despite this pecking order, it is nevertheless not possible to claim that one scheme is necessarily better identified or preferable to another. For this reason, we report the average multiplier across all identification schemes in this paper.

\subsection{Data}

All of the VAR models in this paper are estimated on monthly data for the period from $2012 \mathrm{~m} 6$ to $2016 \mathrm{~m} 4$, when the deposit rate reached zero, the scope for conventional policy easing was exhausted and the ECB implemented negative deposit rate cuts, targeted lending programmes in form of LTROs and asset purchase of sovereign debt (QE) announcements. All of these policies are shown in figure 2. Clearly, the TLTRO was announced close to $\mathrm{QE}$, and cuts to the deposit rate into negative territory were implemented at the same time. Due to this coincidence of policies, it is practically impossible to separate all of their individual effects empirically. Our QE estimate is therefore an upper bound of the ECB's QE policy and will likely reflect the other policies as well.

\section{FIGURE 2}

Nonstandard monetary policy measures announced by the ECB since June 2014

\begin{tabular}{|c|c|c|c|c|c|}
\hline & June 2014 & September 2014 & January 2015 & December 2015 & March 2016 \\
\hline $\mathrm{QE}$ & & $\begin{array}{l}\text { ABS and Covered } \\
\text { Bonds }\end{array}$ & $\begin{array}{l}\text { Sovereign debt added, QE } \\
\text { at EUR60bn per month at } \\
\text { least until Sep } 2016(\mathrm{QE} \\
\text { until a sustained } \\
\text { adjustment in the path of } \\
\text { inflation consistent with } \\
\text { HICP at c. } 2 \%)\end{array}$ & $\begin{array}{l}\text { Time extension (at } \\
\text { least until Mar 2017) } \\
\text { and reinvestment of } \\
\text { principal }\end{array}$ & $\begin{array}{l}\text { Corporate debt added, } \\
\text { QE raised to EUR80bn } \\
\text { per month, and higher } \\
\text { issue share limit for } \\
\text { some issuers }\end{array}$ \\
\hline TLTRO & $\begin{array}{l}\text { TLTRO 1: At a fixed rate } \\
\text { (MRO); Max. Maturity } \\
\text { (Sep 2018); Uptake } \\
\text { depends on net lending; } \\
\text { Mandatory early } \\
\text { repayment if lending } \\
\text { target missed }\end{array}$ & & & & $\begin{array}{l}\text { TLTRO 2: At fixed } \\
\text { MRO rate, or as low as } \\
\text { depo rate if lending } \\
\text { target met }\end{array}$ \\
\hline Negative rate & Depo rate $-10 b p$ & Depo rate at $-20 b p$ & & Depo rate $-30 b p$ & Depo rate $-40 b p$ \\
\hline
\end{tabular}


We date the start of QE in August 2014. Although the Governing Council (GC) only announced its large-scale Asset Purchase Programme (APP) in January 2015, financial markets anticipated QE as early as August 2014, based on President Draghi's and other GC member speeches (eg, see Jackson Hole speech, Aug 2014). In particular, we assume that $50 \mathrm{bn}$ euro per month, of the intial $60 \mathrm{bn}$ euro announcement, was anticipated in August. Our results are not markedly different when we set the first QE date to the actual announcement in January 2015. For monetary policy conducted via the price (interest rate), the announcement and implementation dates coincide. For QE, this is different, but economic theory suggests that the announcement, as opposed to the implementation, should affect economic activity. Our QE series is therefore constructed as the total amount of euro area sovereign debt purchases announced at each meeting, scaled by preannouncement euro area GDP. In particular, we scale the announcement series by 2014Q4 euro area nominal GDP. The resulting time series, together with other ECB policies, is shown in figure 4. For comparison, we also show the UK and US QE anouncement series from Weale and Wieladek (2016) in figure 3.

\section{FIGURE 1}

UK and US QE measures

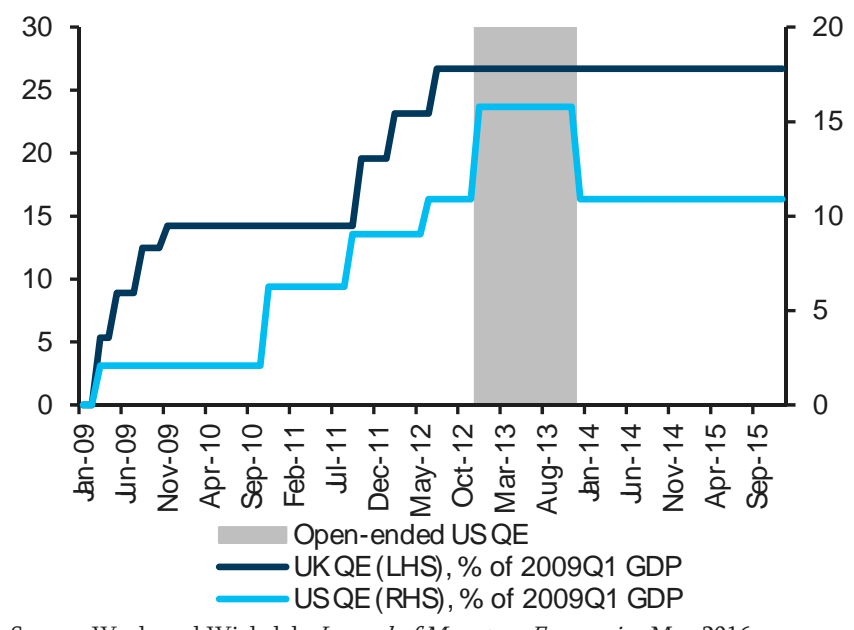

Source: Weale and Wieladek, Journal of Monetary Economics, May 2016.

Note: UK QE is the sum of the MPC's Gilt purchase announcements. US QE is the sum of treasury bond purchase announcements, 'Operation Twist' purchases with a weight of 0.75 and the present value of open-ended treasury bond purchases, which is unwound when tapering is announced,

\section{FIGURE 2}

ECB measures: QE, LTRO and depo rate

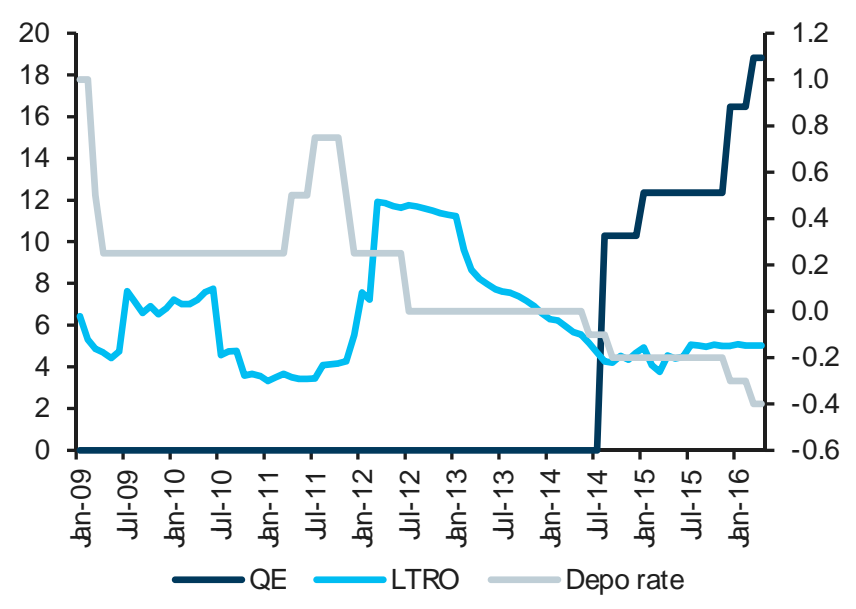

Source: ECB Statistical Data Warehouse, Barclays Research. 
We use the Euro-Coin monthly real GDP index as a measure of monthly GDP for the euro area. For Germany, France, Italy, Portugal and Spain, we interpolate quarterly GDP with monthly industrial production using the Chow-Lin procedure (1971). The monthly indices of core consumer prices are seasonally adjusted EuroStat measures for the euro area, Germany, France, Italy, Portugal and Spain. Share prices for these countries are collected from Haver Analytics and deflated by the corresponding core CPI measures.

We also examine to what extent QE had an impact on other variables in order to explore a number of plausible transmission mechanisms. If the portfolio balance channel is the main transmission channel, one would expect a relatively larger impact on the yields of twenty and thirty-year government bonds. The signaling mechanism, on the other hand, implies a relatively stronger reaction of short-term interest rate futures, namely the three month and one year rate one year ahead. To test for the presence of the uncertainty channel, we study the impact on two financial market indicators of uncertainty: the euro area VIX (implied stock market volatility) and MOVE (weighted average of implied interest rate volatilities at different horizons) indices. Finally, to examine whether or not asset purchases are associated with a credit easing channel, we look for an impact on household and SME interest rates on new lending, as well as the EONIA and 12 months Euribor rates. All of these data are taken from Bloomberg.

\section{Results}

\subsection{Main results - Conditional forecasting exercise.}

Most papers that use Bayesian VARs to asses the impact of QE typically rely on conditional forecasts comparing outcomes with and without the implementation of the policy using the approach of Waggoner and Zha (1999). Baumeister and Benati (2013) and Kapetanios et al (2012) use this approach to quantify the impact of QE on real GDP and CPI in the UK and the US. 
Figure 5: Path of Long rate, real share prices, real GDP and core CPI with and without QE
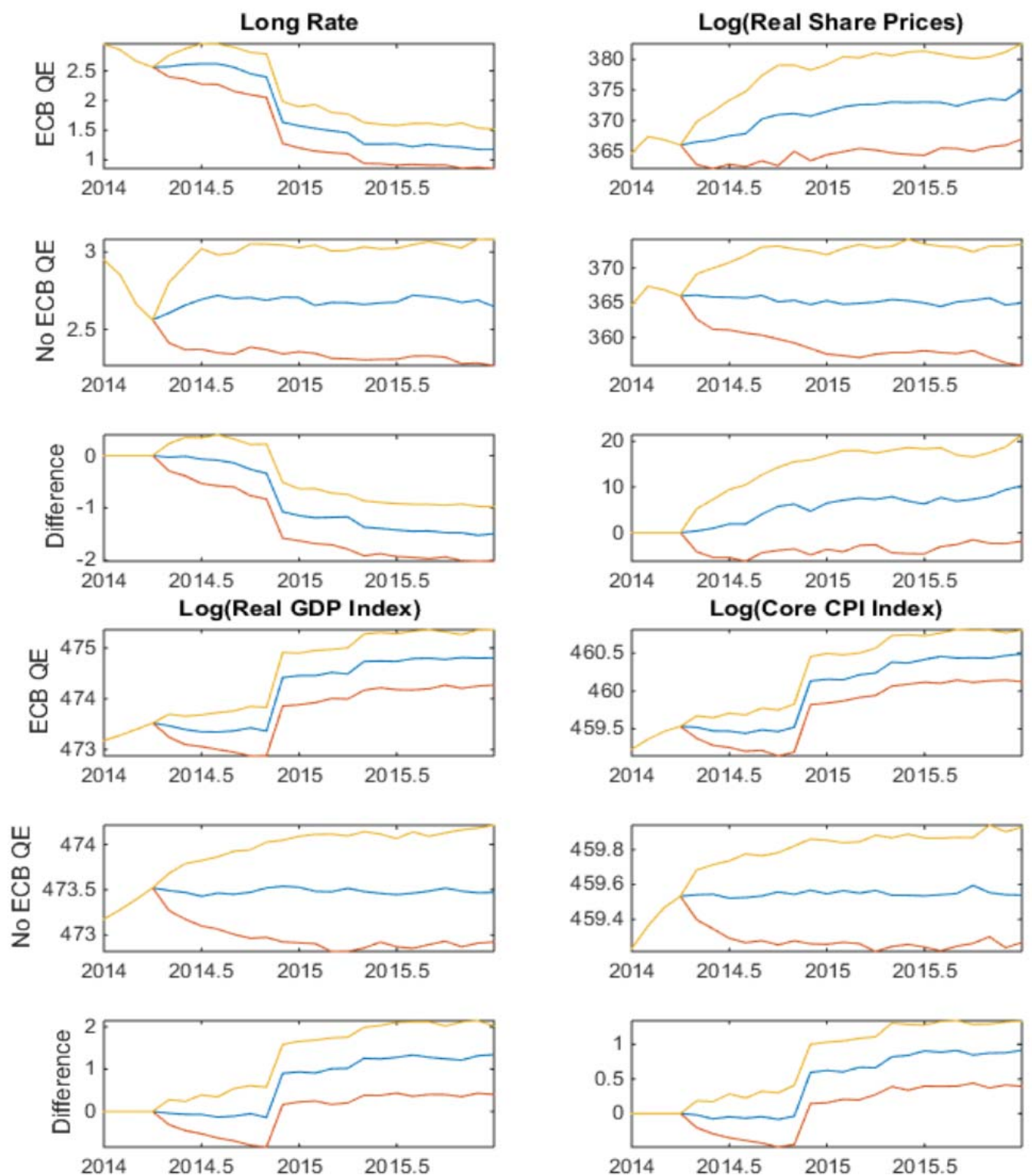

Median Forecast $\longrightarrow$ 16th percentile $\longrightarrow$ 84th percentile

Note: Figure 5 shows the outcomes of a conditional forecasting exercise. The first row labelled 'ECB QE' shows the path of either the long-term interest rate, real share prices, real GDP and core CPI in the presence of QE. The second row labelled 'No ECB QE' shows the responses to these variables in the absence of QE. The third row shows the difference. Where the $16^{\text {th }}$ and $84^{\text {th }}$ percentile exclude zero, the path of a variable is statistically significant from zero. This is true for all of the variables but real share prices.

Giannone, Lenza, Pill and Reichlin (2012) and Altavilla, Giannone and Lenza (2014) use this approach to asses the impact of the ECB's 2008-2009 liquidity injections and the 2013 OMT announcements, respectively. To our knowledge, this is the first paper 
to use this approach to provide an assessment of ECB's initial QE announcements. The results from this exercise are shown in figure 5.

Figure 5 shows the total impact of the ECB's QE on the euro area 10-year government bond yield, real share prices, core CPI and real GDP. The row referred to as 'ECB QE' shows the forecast conditional on the way that QE was announced in the data. The row labelled 'no ECB QE' shows the path of the variables in the absence of QE announcements. The following row shows the difference. Overall these results suggest that the January 2015 QE announcement, together with the aniticipation effect since President Draghi's August 2014 Jackson Hole speech, led to a rise in real GDP and core CPI of $1.3 \%$ and $0.9 \%$, respectively. The 10 -year government bond yield declined by about $160 \mathrm{bp}$ as a result. But there was no statistically significant reaction of real share prices. Compared to the multipliers presented for UK and US QE1 by previous papers, including Baumeister and Benati (2013), Kapetanios, Mumtaz, Theodoris and Stevens (2012) and Weale and Wieladek (2016), the effects documented here are about a half/one third smaller than the comparable impact for the UK/US. We discuss these differences in greater detail in section 3.3.

\subsection{Evidence on Transmission Channels}

Economic theory suggests that asset purchase policy can affect interest rates through several channels (Figure 6):

Starting with the portfolio rebalancing channel, the various mechanisms are presented in a counter-clockwise fashion. In a frictionless world, central bank purchases of government debt have no effect on the yield curve, as financial market participants can easily arbitrage around them (Eggertson and Woodford, 2003). But in the presence of frictions, such as investors that have a preferred habitat for certain parts of the yield curve or transaction costs due to illiquidity, the yield curve will move, affect other asset prices and the real economy by lowering the long-term cost of firm and household finance. The effect of QE on the yield curve and its implication for investors' portfolio re-allocation towards higher- 
yielding assets is often referred to as portfolio rebalancing. This channel has been found to be empirically relevant for the US.

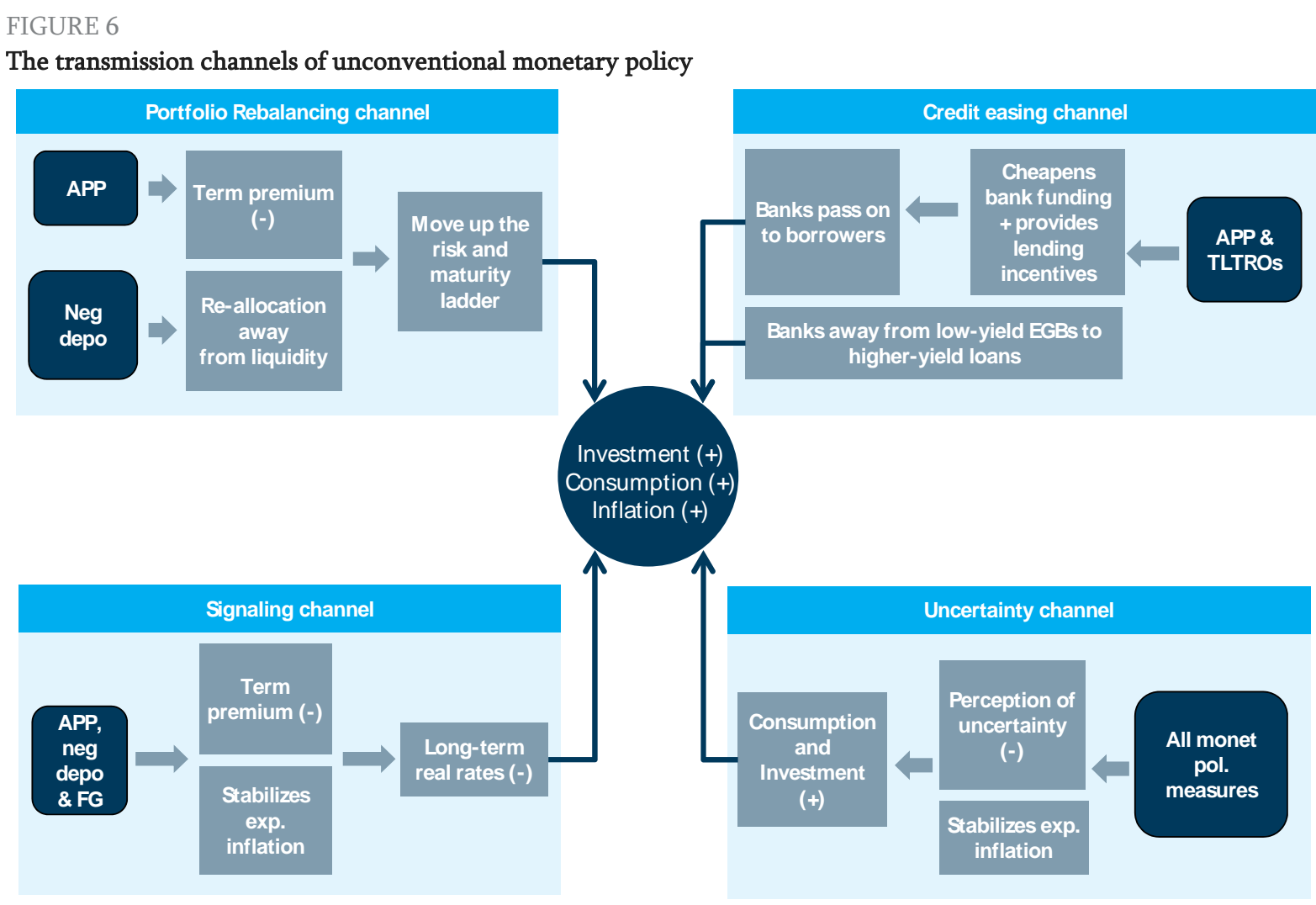

Source: Barclays Research; Note: APP refers to the Asset Purchase Programme; FG refers to Forward Guidance; Neg Depo refers to the Negative Deposit Rate; TLTRO refers to the Targeted Long-Term Refinancing Operations.

Bernanke et al. (2004) argue that QE announcements might signal that the short rate will remain at the zero lower bound for longer. This is typically known as the signalling channel of quantitative easing. The quantitative relevance of this channel is still debated.

The announcement of asset purchases can also serve as a strong signal that the monetary authority is doing 'whatever it takes' to maintain inflation at target, not just to financial markets, but also to households and firms. The effect on the perception of uncertainty and inflation expectations (the uncertainty channel) is therefore an important separate transmission channel. Evidence suggests that this has been a powerful channel in the case of the US and UK. To the extent that QE corresponds to a rise in money supply, the currency could also weaken and support the economy by raising external competitiveness. 
In theory, it is also plausible that there is an important credit easing/bank lending channel to this policy. Asset purchases by the central bank are financed with the issuance of reserves, which are held by the banking system. If the interest rate on reserves is low or negative, banks have an incentive to lend more, and through competition pass on the savings, to maintain their profit margins. There has been no statistical evidence for this channel in the UK and the US, perhaps because the advent of QE coincided with large liquidity injections into the banking system. The ECB's QE episode, which started scarce of liquidity, may thus allow for a better test of this channel.

The reduced-form nature of structural VARs does not allow us to decompose the estimated impacts into contributions from these different transmission channels directly. We can, however, identify variables which we would expect to be affected by asset purchases if each of these mechanisms plays a role in the transmission of this policy.

The portfolio balance channel suggests that, in the presence of frictions in the government bond market, the long-term government bond yield should decline in response to QE announcement shocks. The average maturity of a euro area government bond was 5 years in 2014, which implies greater liquidity premia (transaction costs) in the long end of the market market. To examine if this is the case, we include the yields on a GDP-weighted of euro area government bonds of twenty and thirty years maturity as a sixth variable into our VAR. The results of this exercise are shown in figure 7 . The statistically significant and negative reaction of long-term government bond yields across all identification schemes suggests that this channel does indeed operate.

The signalling channel implies that interest rate futures should respond to QE anouncements. However, if a rise in banking system liquidity pushes the three months and one year interbank rates closer to the ECB's deposit rate, then the corresponding interest futures will decline as well, but this would not be evidence of a signalling channel. For this reason, we examine the impact of the three month and one year rate one year interest rate future as a spread to the corresponding contemporaneous values. The impulse responses in figure 7 show that these spreads respond to QE in each 
identification scheme, providing support for the signalling channel, though the quantitative impact is smaller.

\section{Figure 7: Results for the portfolio balance and signalling channels}
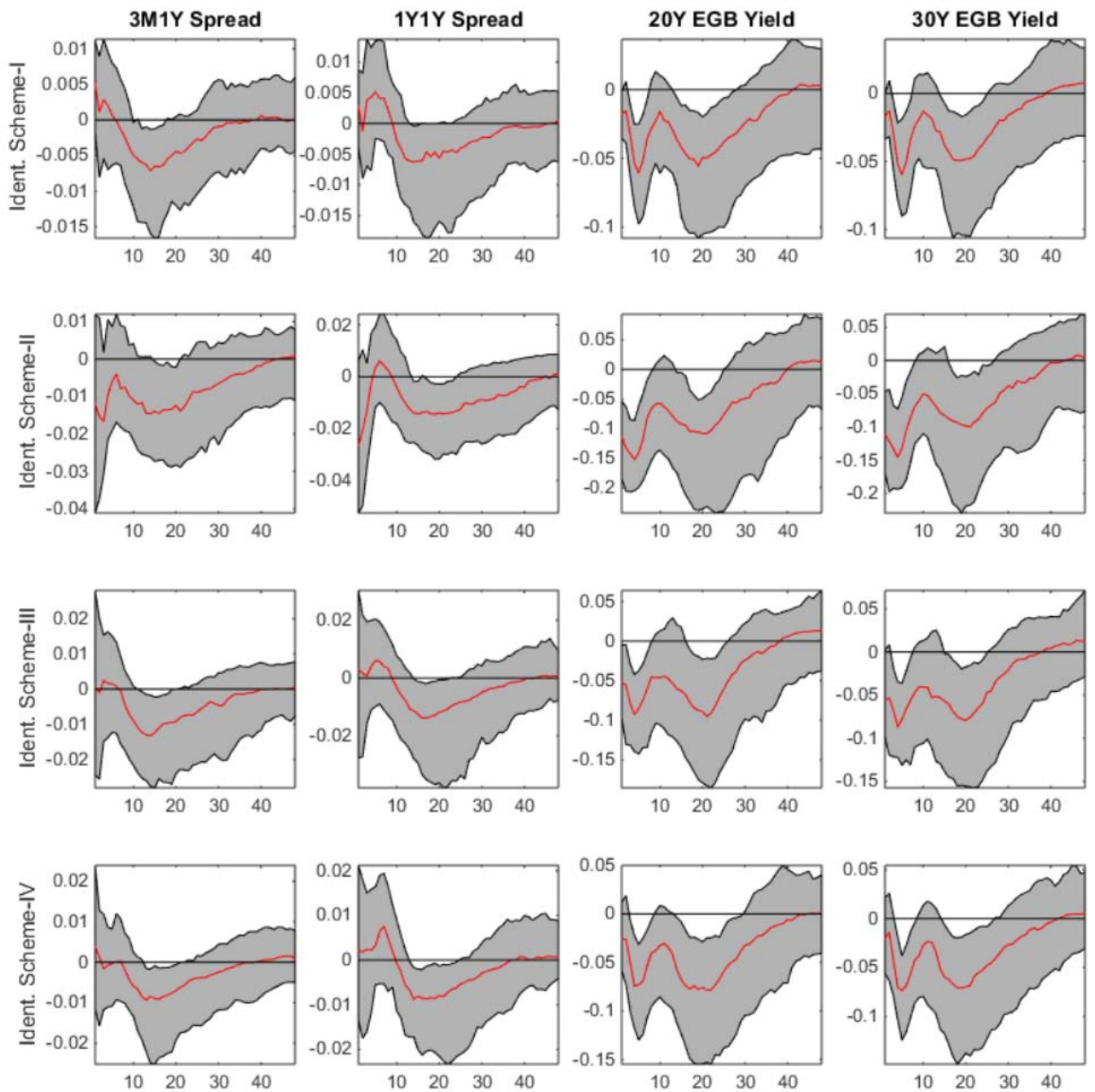

Note: This figure shows, for each of the variables list above, the median impulse responses in response to an unexpected one percent asset purchase announcement as a fraction of 2014Q4 GDP, together with 68\% Bayesian credible sets. We show results for all four identification schemes for the US. 10,100 simulations, with the first 10,000 as burn-in, were used to generate the responses. $3 \mathrm{M} 1 \mathrm{Y}$ and $1 \mathrm{Y} 1 \mathrm{Y}$ are the 3 month and one year interest rate futures one year ahead, expressed as a spread to the corresponding contemporaneous values, $20 \mathrm{Y}$ and $30 \mathrm{Y}$ EGB Yield are the yields on 20 and 30 year GDP-weighted euro area government debt. The vertical axis is expressed in percent, while the horizon axis indicates the number of monthly time periods since the anouncement. 
Figure 8: Results for the uncertainty and exchange rate channels
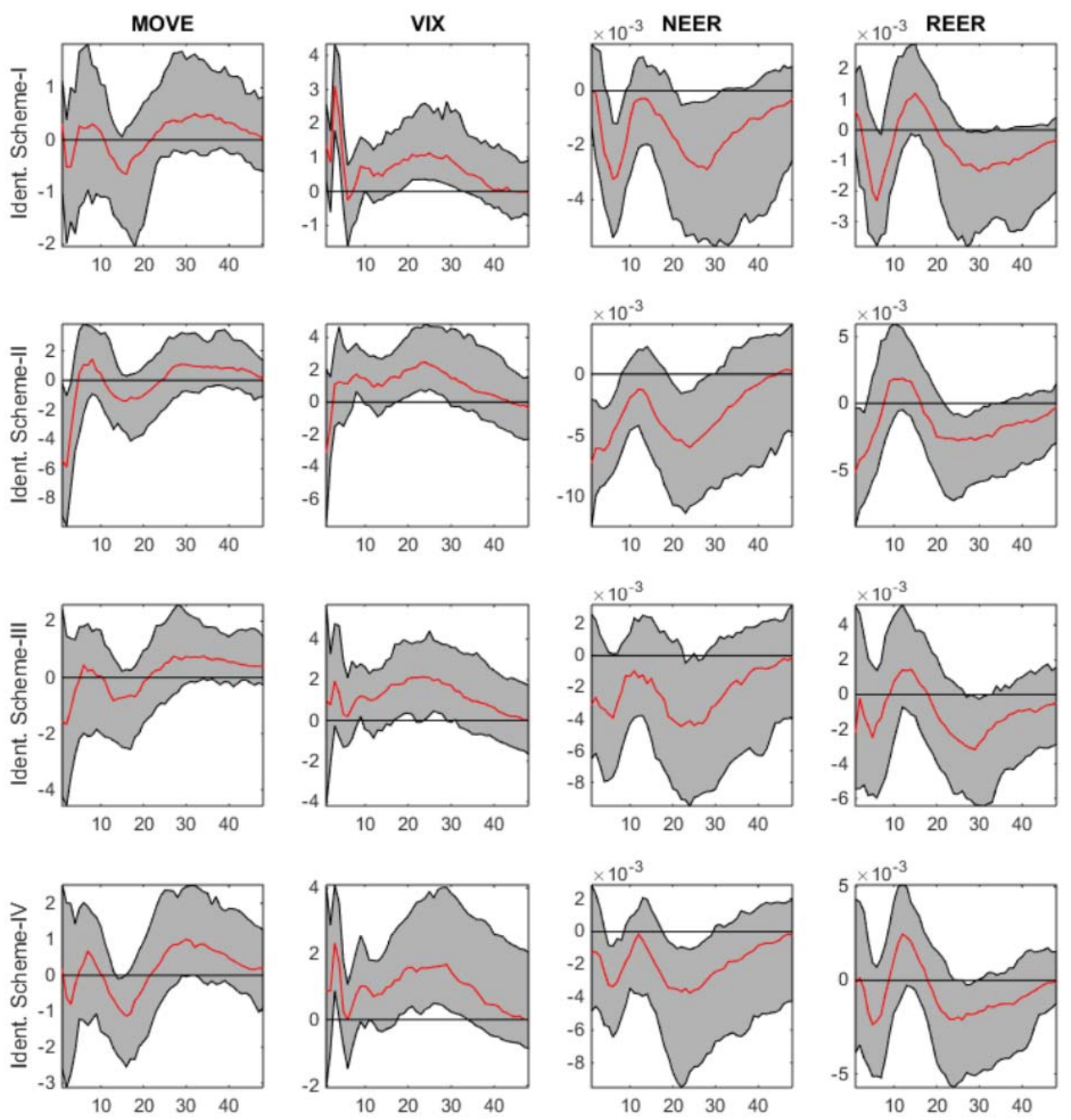

Note: This figure shows, for each of the variables list above, the median impulse responses in response to an unexpected one percent asset purchase announcement as a fraction of 2014Q4 GDP, together with 68\% Bayesian credible sets. We show results for all four identification schemes for the US. 10,100 simulations, with the first 10,000 as burn-in, were used to generate the responses. VIX and MOVE refer to two different indices of financial market uncertainty, as explained in the data section, NEER and REER refer to the nominal and real effective exchange rate respectively. The vertical axis is expressed in percent, while the horizon axis indicates the number of monthly time periods since the anouncement.

Weale and Wieladek (2016) argue that the uncertainty channel was an important transmission mechanism in the case of UK and US QE. Here we test for this channel in the case of ECB QE. Figure 8 shows the impulse responses of the euro area VIX and MOVE in response to a $\mathrm{QE}$ shock. The response of the implied volatility of interest rates (MOVE) is only statistically significant in one specification. The response of VIX is positive and statistically significant throughout. Yet a positive sign is the opposite that 
one would expect from a channel that works primarily through reducing financial market measures of uncertainty such as VIX and MOVE. Overall this suggests that, unlike in the UK and the US, the uncertainty channel does not operate in the euro area. The response of the nominal, but not the real, effective exchange rate in figure 8 is consistent with the presence of the exchange rate channel in a statistically significant way.

\section{Figure 9: Results for the credit easing channel}
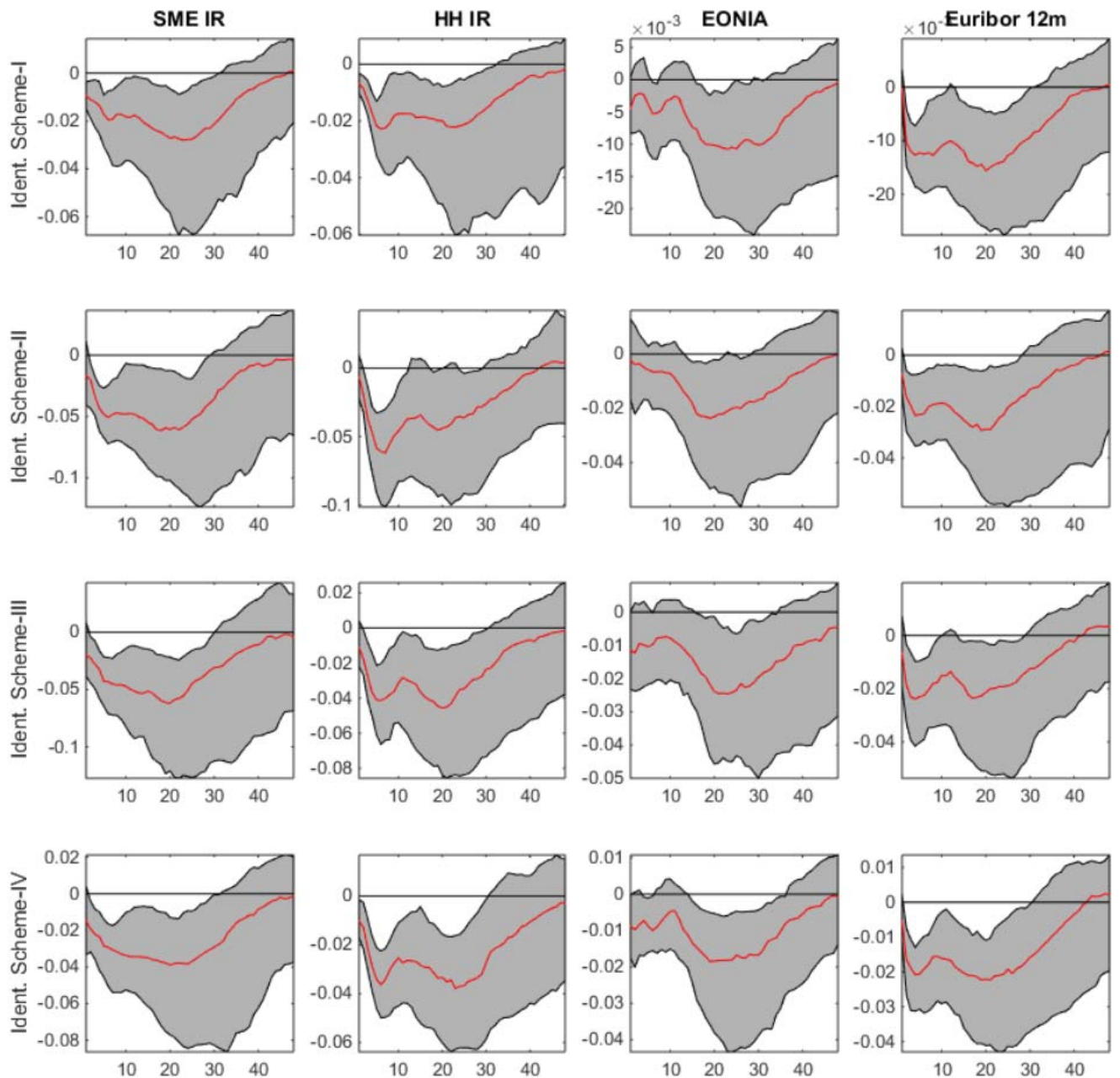

Note: This figure shows, for each of the variables list above, the median impulse responses in response to an unexpected one percent asset purchase announcement as a fraction of 2014Q4 GDP, together with 68\% Bayesian credible sets. We show results for all four identification schemes for the US. 10,100 simulations, with the first 10,000 as burn-in, were used to generate the responses. SME and $\mathrm{HH}$ IR refer to effective rates on new lending to households and SMEs, respectively. EOINA is the overnight, and Euribor $12 \mathrm{~m}$, the 12 month euro interbank rate. The vertical axis is expressed in percent, while the horizon axis indicates the number of monthly time periods since the anouncement. 
In theory, asset purchases of sovereign debt could also affect the economy by injecting liquidity into the banking system, via the issuance of reserves, and hence pushing interbank rates closer to the deposit rate on reserves. In the case of the ECB, this would mean that OIS overnight rate (EONIA) and the interbank rate twelve months out (EURIBOR) would be pushed closer to the deposit rate and into negative territory. If, through competition, this is passed to household and SME borrowers, this type of credit easing is an independent channel of transmission. Figure 9 shows the responses of the overnight OIS (EONIA) and 12-month interbank (EURIBOR) rates to a 1\% rise QE announcement as a fraction of GDP. Both of these variables react in a negative and statistically significant way across all of the identification schemes in figure 9. Simillary, SME and household interest rates on new lending decline as well. Overall this suggests that asset purchases in the euro area also likely eased credit conditions by injecting additional liquidity into the banking system through the issuance of reserves. In that sense the ECB's QE policy helped to reinforce the negative deposit rate policy.

\subsection{Country specific results and comparison to the UK and US experience}

Thus far our analysis has focused on the aggregate euro area impact of QE. But it is also possible to examine the impact on the largest euro area countries, by replacing euro area core CPI, the 10-year government bond yield, real GDP and share prices with the corresponding variables for the four biggest euro area countries: Germany, France, Italy and Spain. The results of impulse response analysis on these countries and the euro area are presented in table 2. For ease of exposition, we only show the peak impact impulse responses in the table, with the corresponding figures shown in appendix A.

Table 2 suggest that in response to a $1 \%$ QE announcement shock, euro area real GDP rises by $0.11 \%$ or 11 basis points, on average across all identification schemes. Core CPI rises by 7.5 basis points, and the long rate declines by 9.3 basis points. In terms of country-specfic results, in response to a 1\% QE announcement in terms of 2014 Q4 GDP, real GDP rises the most in Spain and the least in Italy. Spain underwent a restructuring of 
the banking system and implemented significant structural reforms, which probably amplified the effect of QE. It also benefits from the highest share of floating-rate mortgage debt among these countries; over 95\% of the entire stock of mortgage debt is linked to the $12 \mathrm{~m}$ Euribor rate. The mortgage to GDP ratio in Spain is 50\%. Assuming that rates on floating rate mortgages fell $77 \mathrm{bp}$, in line with the decline on rates on new lending, this would immediately raise household cash balances by $0.385 \%$ of GDP. In Italy, where the mortgage to GDP ratio is $17 \%$, this effect would be expected to be much smaller.

Table 2 - Peak impulse response to a 1\% QE announcement shock

\begin{tabular}{|c|c|c|c|c|c|}
\hline Variable/Country & Identification I & Identification II & Identification III & Identification IV & Average \\
\hline \multicolumn{6}{|c|}{ Euro Area } \\
\hline Real GDP & 8.0 & 14.7 & 10.9 & 10.8 & 11.1 \\
\hline Core CPI & 5.7 & 10.0 & 6.9 & 7.5 & 7.5 \\
\hline Long Rate & -5.7 & -14.9 & -9.0 & -7.5 & -9.3 \\
\hline \multicolumn{6}{|c|}{ Germany } \\
\hline Real GDP & 6.0 & 17.7 & 9.9 & 9.5 & 10.8 \\
\hline Core CPI & 4.8 & 15.9 & 8.0 & 8.5 & 9.3 \\
\hline Long Rate & -7.6 & -11.8 & -8.4 & -8.4 & -9.1 \\
\hline \multicolumn{6}{|c|}{ France } \\
\hline Real GDP & 7.6 & 13.6 & 11.3 & 11.0 & 10.9 \\
\hline Core CPI & 3.2 & 7.2 & 4.8 & 4.1 & 4.8 \\
\hline Long Rate & -10.5 & -12.9 & -10.6 & -10.6 & -11.1 \\
\hline \multicolumn{6}{|c|}{ Italy } \\
\hline Real GDP & 4.0 & 7.0 & 5.6 & 5.1 & 5.4 \\
\hline Core CPI & 2.8 & 5.7 & 4.3 & 4.5 & 4.3 \\
\hline Long Rate & -11.0 & -18.2 & -13.9 & -15.2 & -14.5 \\
\hline \multicolumn{6}{|c|}{ Portugal } \\
\hline Real GDP & 6.2 & 19.6 & 8.0 & 8.5 & 10.6 \\
\hline Core CPI & 4.1 & 6.6 & 4.7 & 5.8 & 5.3 \\
\hline Long Rate & -7.5 & -38.4 & -11.6 & -11.7 & -17.3 \\
\hline \multicolumn{6}{|c|}{ Spain } \\
\hline Real GDP & 7.2 & 34.3 & 18.9 & 17.6 & 19.5 \\
\hline Core CPI & 1.9 & 8.2 & 4.0 & 3.6 & 4.4 \\
\hline Long Rate & -4.8 & -22.5 & -12.3 & -11.6 & -12.8 \\
\hline
\end{tabular}


An intermediate case is Portugal: an economy with reforms implemented as part of the 2011-14 financial rescue program, a high degree of leverage including through mortgage debt, but a fragile banking sector. The multiplier for this economy is twice as high as Italy's, but only half as large as Spain's. While not foolproof evidence, these results suggest that in the absence of structural reforms and a clean-up of the banking system, Italy will continue to benefit the least from QE among large euro area countries.

The overall impact of QE on core CPI is small across all EA4. Nonetheless, the effect on core CPI in Germany is larger than for Italy or Spain. This probably reflects the state of the business cycle: the same monetary impulse will create more wage and price pressure in an economy that is running close to capacity, as opposed to one where resources are abundant. Indeed, unemployment rates in Spain and Italy are the highest in this group of countries, which is why the core CPI response is smaller there. On the other hand, Germany is running close to capacity, so the core CPI response there is larger. But the numbers in Figure 11 provide the total effect compared with a world without QE. The fact that, for example, German core CPI inflation has not increased substantially does not mean that the policy has not been effective, as monetary policy cannot be assessed by looking out through the window (Praet, April 2016). Rather, this is perhaps a reflection of the deflationary headwinds that Germany is facing.

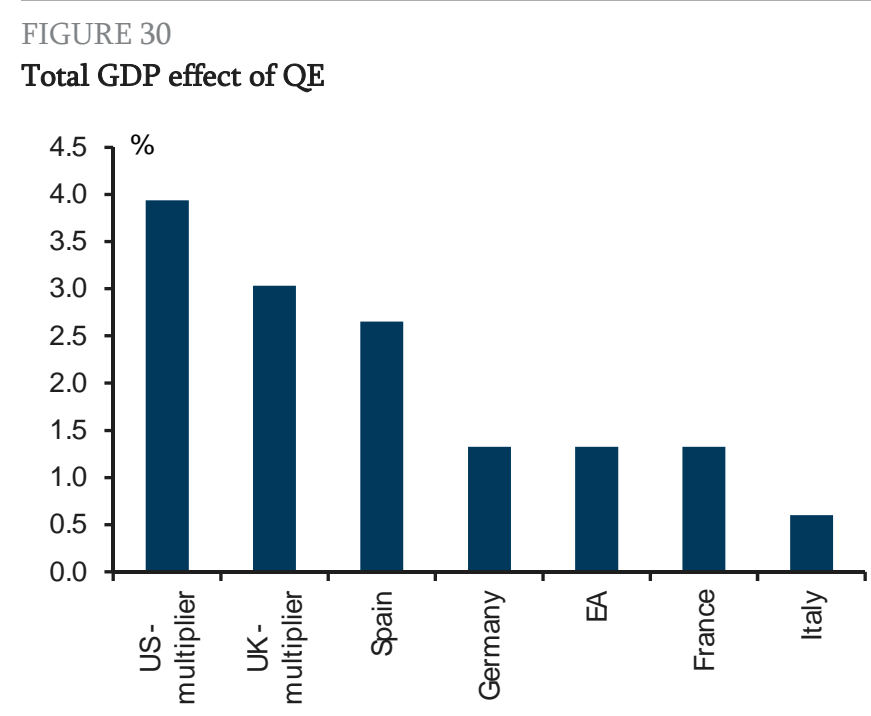

Source: Weale and Wieladek (2016). Barclays Research

\section{FIGURE 11 \\ Total core CPI effect of QE}

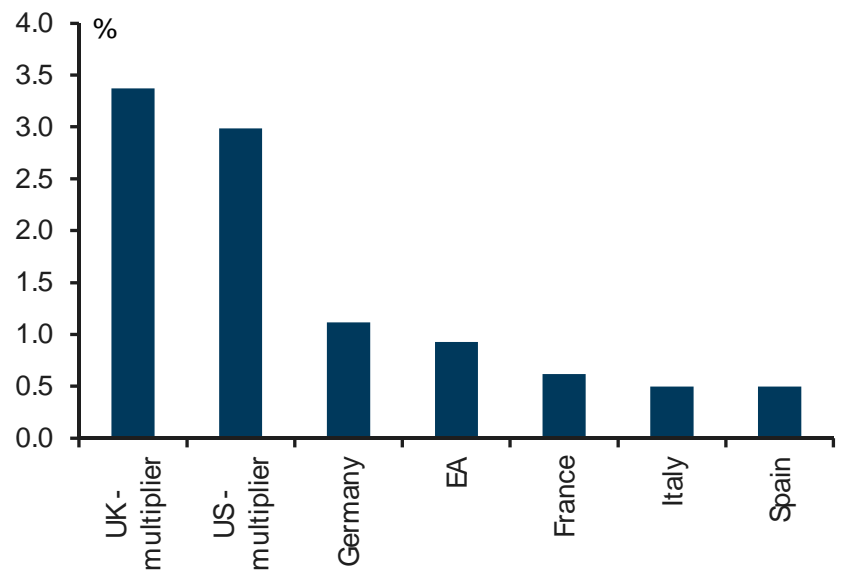

Source: Weale and Wieladek (2016). Barclays Research 
An interesting and relevant question is whether or not the ECB's QE will have the same impact as in the UK and the US. Since we use the same methodology as in Weale and Wieladek (2016), it is possible to compare the total impact on euro area variables, by scaling the ECB impact up/down with the multipliers presented in their paper. The results of this exercise are shown in Figures 10 and 11. Compared to a world without QE, the results suggest that the long-run level of real GDP and core CPI were approximately $1.3 \%$ and $1.0 \%$, respectively, higher as a result of the policy. These estimates also show that the effect of QE in the euro area is considerably smaller than in the UK and the US. Indeed, it would have been twice (three times) as high if the transmission was as powerful as in the UK (US). It is perhaps easier to compare the UK with the euro area than the US. Not only is there the geographical proximity, but the Bank of England mostly purchased sovereign debt and also used targeted credit policies, in the form of the Funding for Lending scheme, to stimulate aggregate demand. This policy mix is much closer to the ECB's. The ECB's QE has a better inflation-output trade-off than in the UK and the US, generating only $0.8 \%$ inflation for each percent of real GDP growth.

FIGURE 4

ECB QE total effect on the 10yr EGB rate

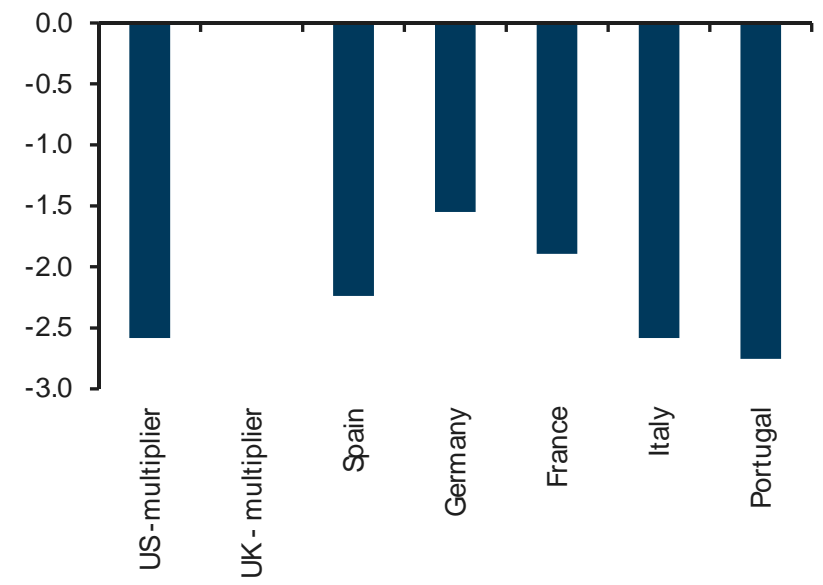

Source: Barclays Research

\section{FIGURE 5 \\ ECB QE total effect on share prices}

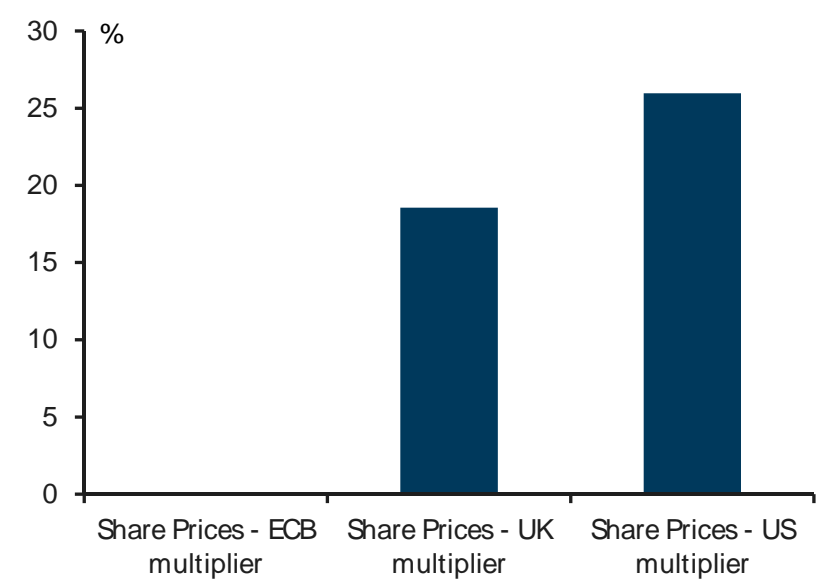

Source: Barclays Research

There are a number of explanations for the difference in the QE multiplier across countries. One is the timing: UK and US QE were implemented very soon after interest 
rates in these countries reached the zero lower bound and at the height of the 2008-09 global financial crises. As such, Weale and Wieladek (2016) might overestimate the actual effect. Yet the multipliers stay similar if only QE2 and QE3 are considered. This difference might also reflect the difference in transmission channels.

To shed further light in this issue, we also consider the impact on long rate and real share prices. Figure 12 suggests that the impact on the long rate is broadly similar. But In the UK and US, there is evidence that QE reduced financial market and household level measures of uncertainty. But this does not operate in the euro area; there is no statistically significant effect on share prices (Figure 13). Indeed, if the effect had been the same as in the UK/US, share prices would have been $18-26 \%$ higher. This is consistent with the idea that ECB QE does not affect risk premia and that the wealth effects are perhaps smaller.

\section{Conclusion}

In response to the 'Great Recession,' the Federal Reserve and Bank of England pulled all of the available levers and persisted with aggressive monetary policy, until an economic recovery was entrenched. With hindsight, these policies worked incredibly well, given the circumstances, in contributing to a sustainable recovery. The ECB adopted a more cautious approach, implementing policies such as the LTRO, with an explicit exit strategy as a design feature. With the announcement of QE, the ECB has now embarked on a similar path to the Bank of England and the Federal Reserve. But will the same policy produce similarly succesful outcomes?

We provide a first macroeconometric assessment. ${ }^{3}$ Our strategy relies on adopting the same BVAR methodology that has been previously used to study this policy in the UK and US (Weale and Wieladek, 2016). We use this framework in a number of ways: First, we assess the total macroeconomic impact of the ECB's QE by comparing data outturns to a counterfactual where is not announced. Second, we use structural VAR analysis to explore the impact of this policy country-by-country and through alternative transmission channels. Finally, we compare the impact of the policy to the impact in the UK and the US, with the estimates provided in Weale and Wieladek (2016). Our results

\footnotetext{
${ }^{3}$ See Altavilla, Carboni and Motto (2015) for a first financial market event study if the ECB’s policy.
} 
suggests that Euro area real GDP and core CPI would have been 1.3\% and $0.9 \%$ lower in the absence of this policy. We find that the policy is mostly transmitted through the portfolio balance, signaling, exchange rate and credit easing channels. But unlike in the UK and the US, the uncertainty channel does not seem to operate in the case of the ECB's QE. This is plausibly one reason why real share prices do not seem to react to the ECB's $\mathrm{QE}$, despite a reduction in 10-year government bond yields of 160 basis points. The impact on Spanish real GDP is four times as large as the impact on Italian GDP. We hypothesise that this could be due differences in structural and banking sector reforms among these countries. The case of Portugal, a country which underwent significant structural, but not banking sector, reform supports this assertion. Compared to the UK and the US though, the ECB's QE does not seem very powerful: For real GDP the effects are two to three times smaller, and even smaller still for core CPI. Overall these results suggest that, in the absence structural and banking sector reforms, countries like Italy will continue to benefit least from the ECB's QE policy.

Of course, an important caveat of our study is that the TLTRO was announced close to $\mathrm{QE}$, and cuts to the deposit rate into negative territory were implemented at the same time. Due to this coincidence of policies, it is practically impossible to separate all of their individual effects empirically. But this would bias the effect upwards and can not explain why the effect of the ECB's QE has not been as powerful as in the UK and the US.

Clearly, the analysis presented in this paper is just the beginning of understanding the macroeconomic consequences and transmission channels of the ECB's QE policies. Overall we believe that our results are good news: The ECB's latest policy package has had a significant impact on real GDP and core CPI. And our estimates imply that without the Governing Council's December 2015 and March 2016 anouncements, euro area real GDP and core CPI would be $0.9 \%$ and $0.45 \%$ lower in the medium run. Nevertheless an important area for future research is to better understand the interaction of this policy with structural and banking sector reform to ensure that all euro area countries can reap the benefits from this policy. 


\section{References}

Altavilla, C, Carboni, G and Motto, R (2015). 'Asset purchase programmes and financial markets: lessons from the euro area', ECB Working Paper Series 1864.

Altavilla, C, Giannone, D and Lenza, M (2014). 'The Financial and Macroeconomic Effects of OMT Anouncements', ECB Working Paper Series 1707.

Arias, J, Rubio-Ramirez, J and Waggoner, D (2014). 'Inference Based on SVARs with Sign and Zero Restrictions: Theory and Applications', Working Paper, Duke University. Bauer, M and Rudebusch, G (2014). 'The signaling channel for Federal Reserve Bond purchases', International Journal of Central Banking, Vol10(3), pages 223-289.

Baumeister, C and Benati, L (2013). 'Unconventional Monetary Policy and the Great Recession: Estimating the Macroeconomic Effects of a Spread Compression at the Zero Lower Bound,' International Journal of Central Banking. Vol. 9(2), pages 165-212, June. Bernanke, B. S., V. R. Reinhart and B.P.Sack. (2004). "Monetary Policy Alternatives at the Zero Bound: an Empirical Assessment”. Finance and Economics Discussion Series. No 2004-48. Federal Reserve Board.

Canova, F and de Nicoló, G (2002). 'Monetary Disturbances Matter for Business Fluctuations in the G7', Journal of Monetary Economics. Vol. 49(6), pages 1131-59. Eggertson, GB. and Woodford, M. (2003). 'The Zero Bound on Interest Rates and Optimal Monetary Policy'. Brookings Papers on Economic Activity. Vol 34, pages 139235.

Giannone, D., M. Lenza, Pill, H and Reichlin, L. (2012). “The ECB and the Interbank Market”. Economic Journal. Vol 122(564). Pp F467-486.

Giannone, D., M. Lenza and G.E. Primiceri. (2015). "Prior Selection for Vector Autoregressions". Review of Economics and Statistics. Vol 97. Pp 436-451.

Harrison, R (2012). 'Asset purchase policy at the effective lower bound for interest rates'. Bank of England Working Papers No. 444.

Kapetanios, G, Mumtaz, H, Stevens, I and Theodoridis, K (2012). 'Assessing the economywide effects of quantitative easing ', Economic Journal. Vol. 122(564), pages F316-47. 
Litterman, R B (1986). 'Forecasting with Bayesian Vector Autoregressions - Five Years of Experience'. Journal of Business \& Economic Statistics. Vol. 4(1), pages 25-38.

Rubio-Ramírez, J F, Waggoner, D F and Zha, T (2010). 'Structural Vector Autoregressions: Theory of Identification and Algorithms for Inference'. Review of Economic Studies. Vol 77(2), pages 665-696.

Uhlig, H (2005). 'What are the Effects of Monetary Policy on Output? Results from an Agnostic Identification Procedure'. Journal of Monetary Economics. Vol. 52(2), pages 381-419.

Vayanos, D and Vila, J (2009). 'A Preferred-habitat Model of the Term Structure of Interest Rates'. London School of Economics Mimeo.

Waggoner, D.F and T. Zha. (1999). "Conditional Forecasts in Dynamic Multivariate Models”. Review of Economics and Statistics. Vol 81. Pp 639-651.

Weale, M and Wieladek, T (2016). "What are the macroeconomic effects of asset purchases?" Journal or Monetary Economics, Volume 79, May 2016, pages 81-93. 


\section{APPENDIX A: Euro Area and Individual country impulse responses.}

Figure A1: Euro area impulse responses to a $1 \%$ QE announcement shock
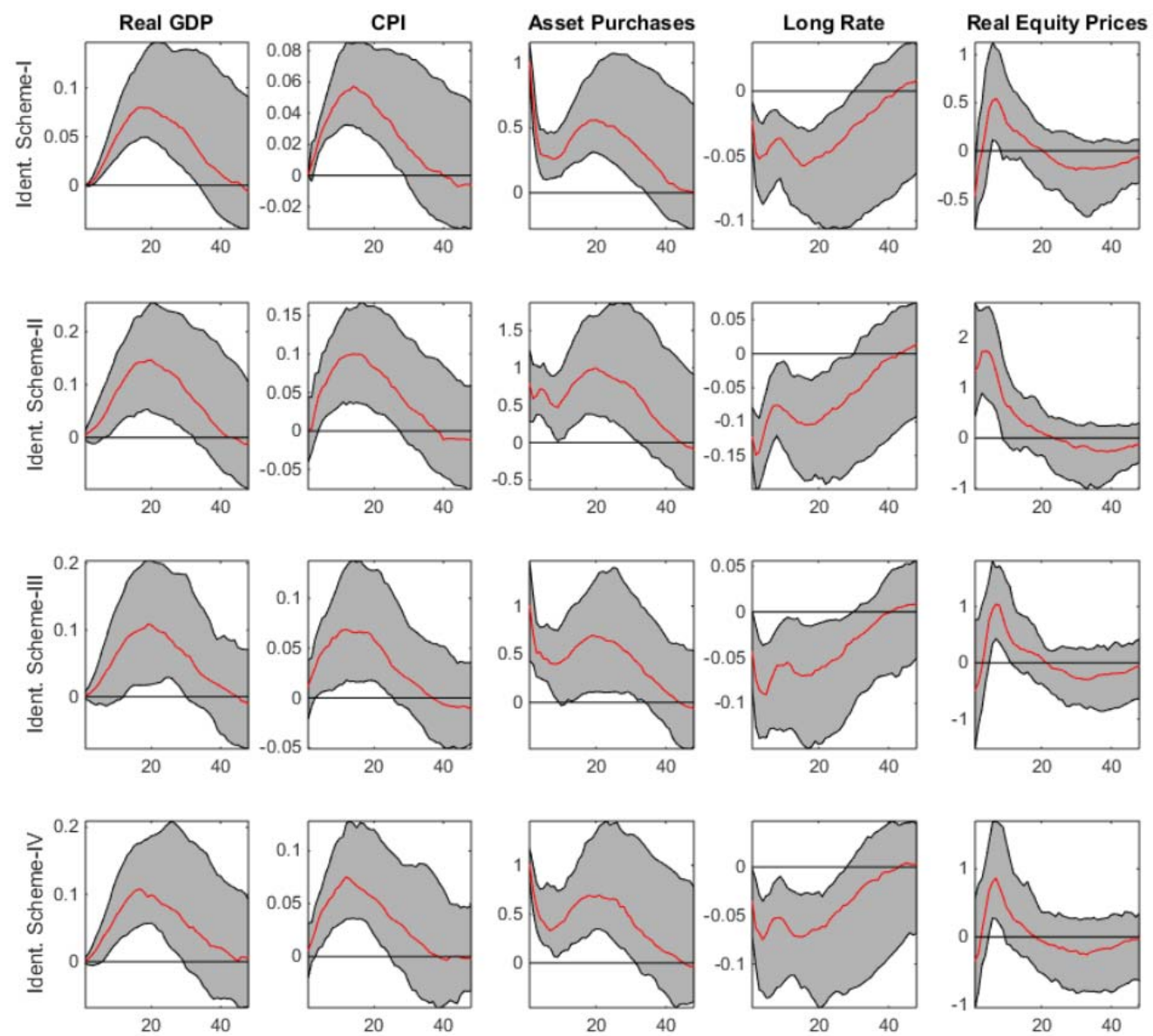

\section{8th Quantile —Median}

Note: This figure shows, for each of the variables in our model, the median impulse responses in response to an unexpected one percent asset purchase announcement as a fraction of 2014Q4 GDP, together with 68\% Bayesian credible sets. We show results for all four identification schemes for the euro area. 10,100 simulations, with the first 10,000 as burn-in, were used to generate the responses. The vertical axis is expressed in percent, while the horizon axis indicates the number of monthly time periods since the anouncement. 
Figure A2: Germany impulse responses to a 1\% QE announcement shock
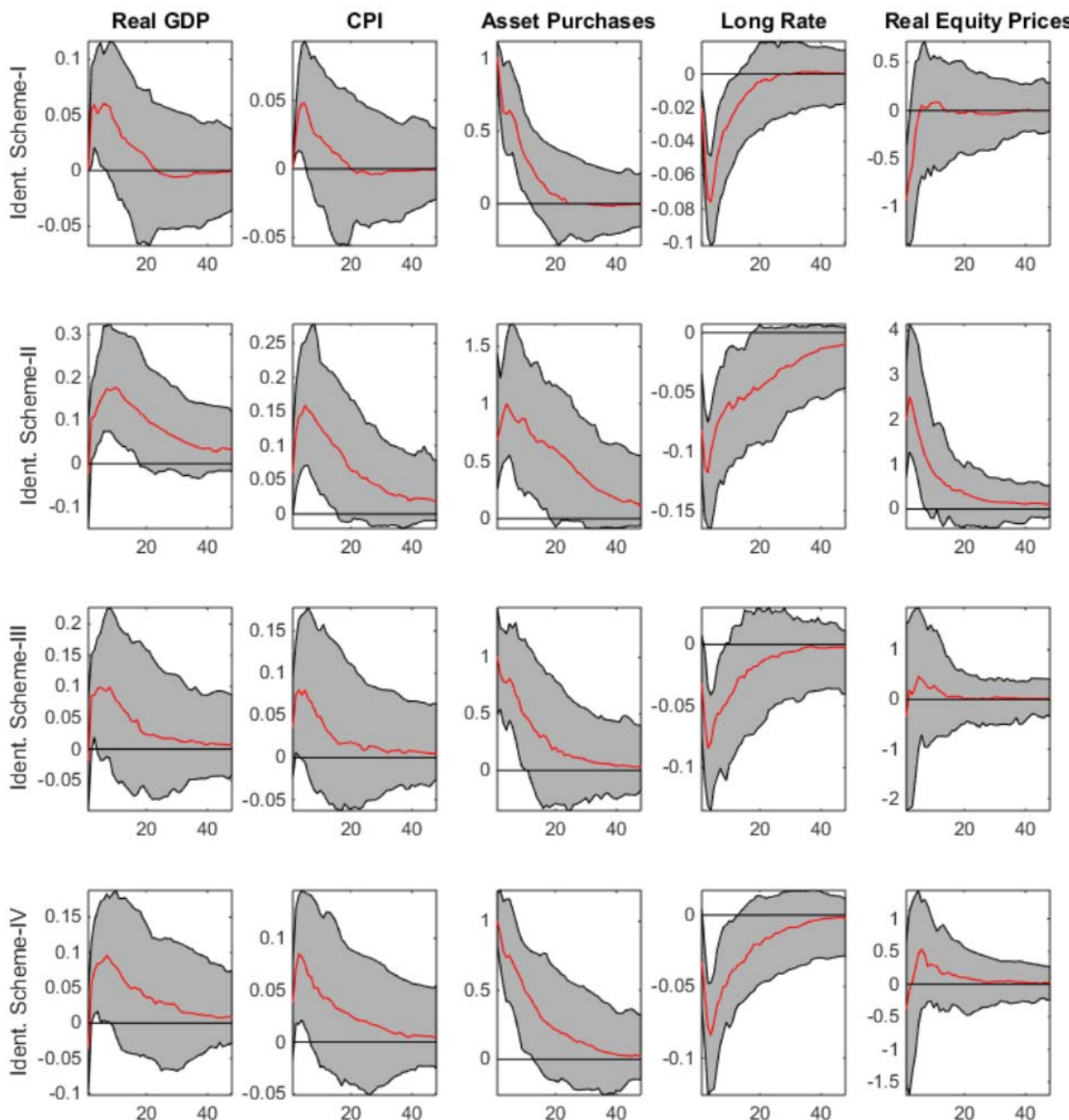

68th Quantile — Median

Note: This figure shows, for each of the variables in our model, the median impulse responses in response to an unexpected one percent asset purchase announcement as a fraction of 2014Q4 GDP, together with 68\% Bayesian credible sets. We show results for all four identification schemes for Germany. 10,100 simulations, with the first 10,000 as burn-in, were used to generate the responses. The vertical axis is expressed in percent, while the horizon axis indicates the number of monthly time periods since the anouncement. 
Figure A3: France impulse responses to a $1 \%$ QE announcement shock
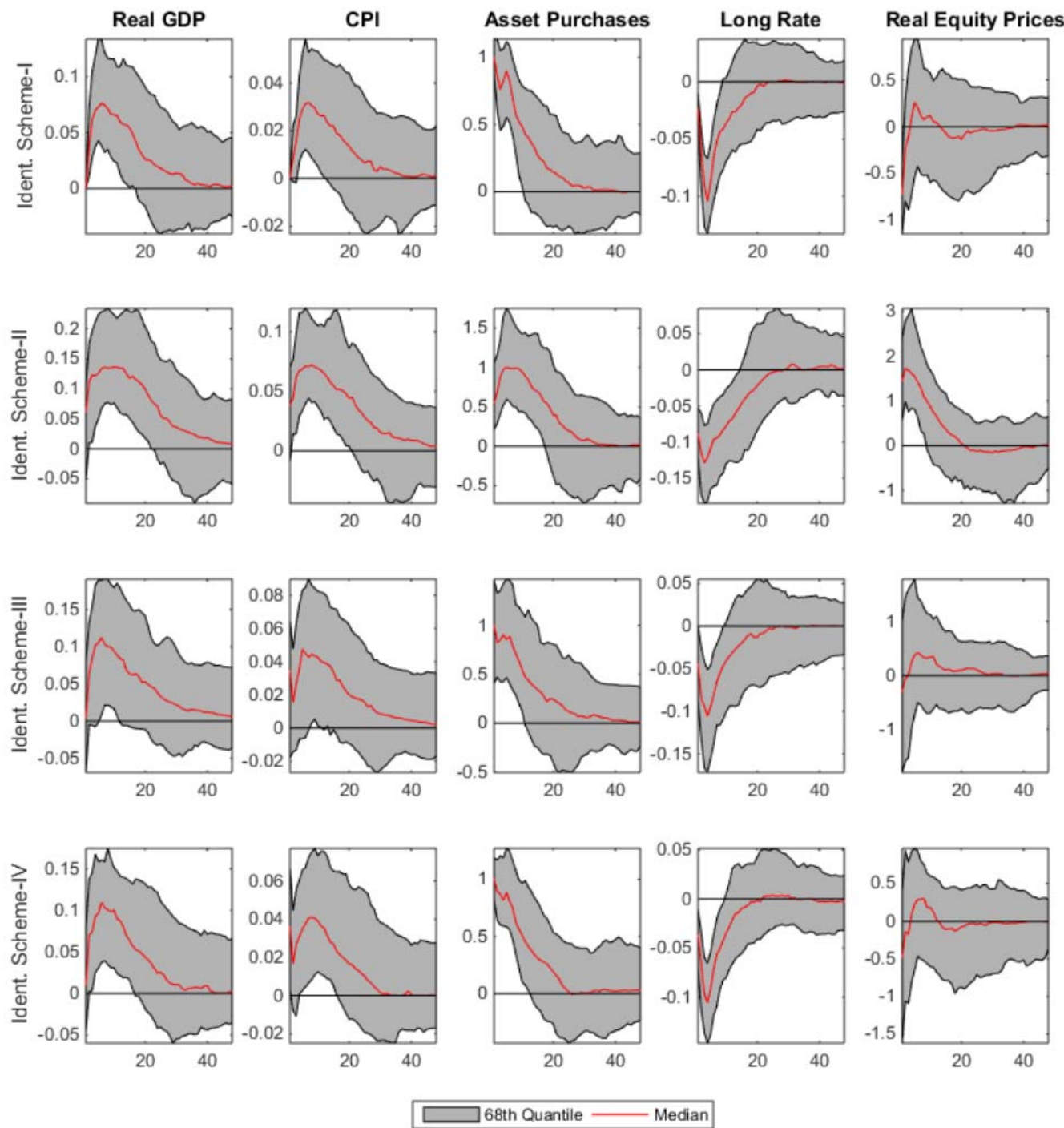

Note: This figure shows, for each of the variables in our model, the median impulse responses in response to an unexpected one percent asset purchase announcement as a fraction of 2014Q4 GDP, together with 68\% Bayesian credible sets. We show results for all four identification schemes for France. 10,100 simulations, with the first 10,000 as burn-in, were used to generate the responses. The vertical axis is expressed in percent, while the horizon axis indicates the number of monthly time periods since the anouncement. 


\section{Figure A4: Italy impulse responses to a $1 \%$ QE announcement shock}
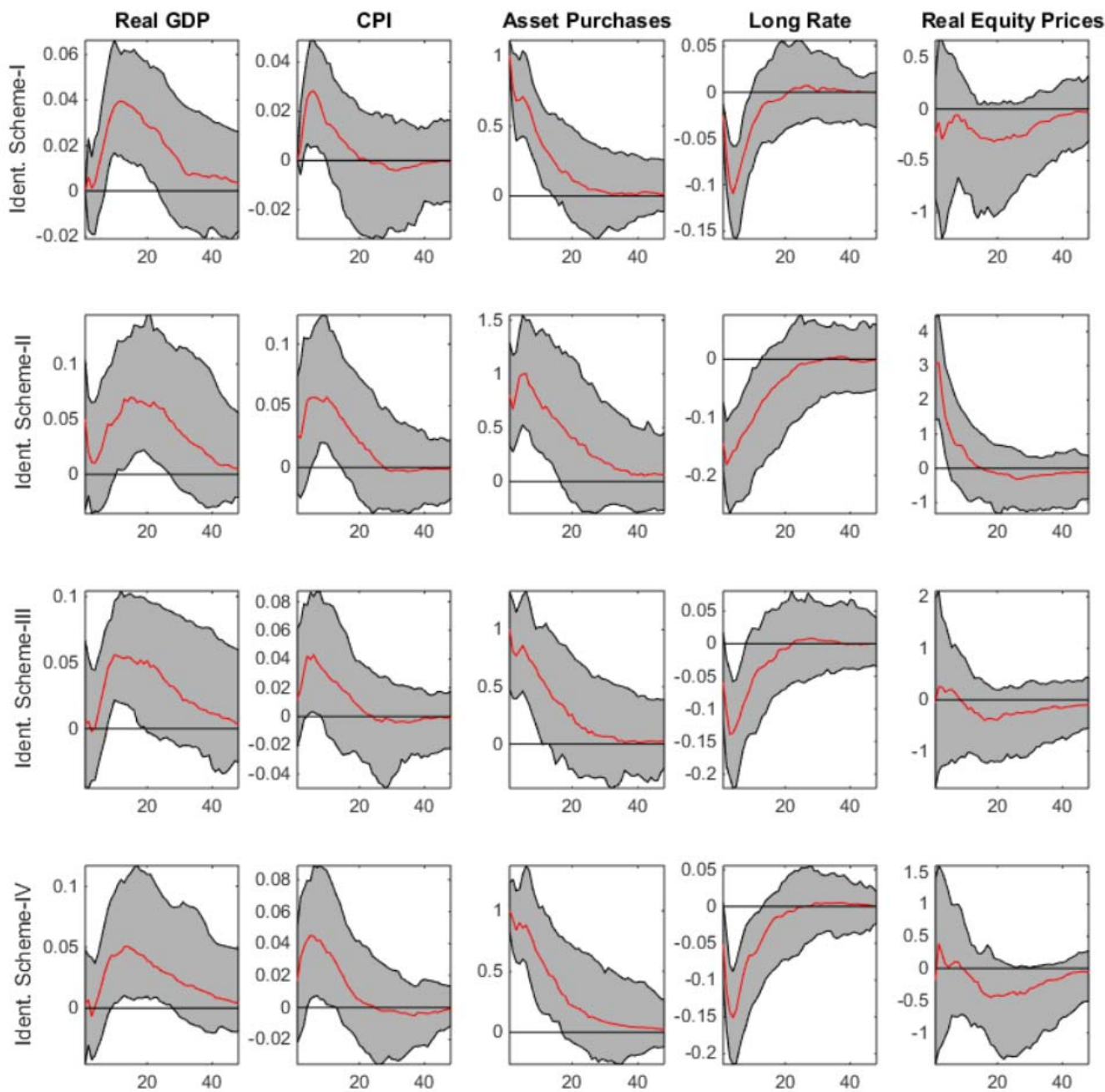

68th Quantile — Median

Note: This figure shows, for each of the variables in our model, the median impulse responses in response to an unexpected one percent asset purchase announcement as a fraction of 2014Q4 GDP, together with 68\% Bayesian credible sets. We show results for all four identification schemes for Italy. 10,100 simulations, with the first 10,000 as burn-in, were used to generate the responses. The vertical axis is expressed in percent, while the horizon axis indicates the number of monthly time periods since the anouncement. 


\section{Figure A5: Portugal impulse responses to a 1\% QE announcement shock}
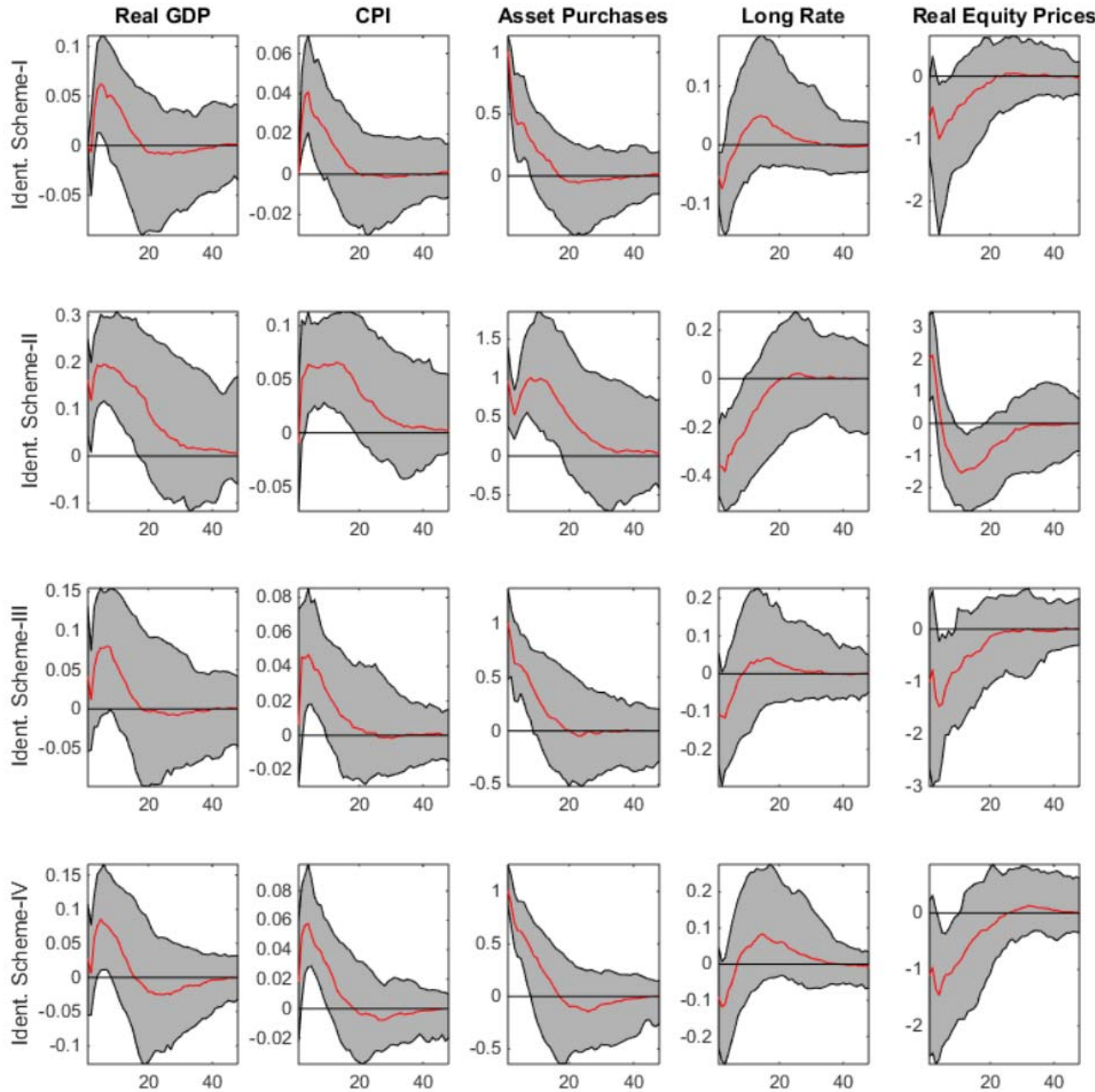

68th Quantile —Median

Note: This figure shows, for each of the variables in our model, the median impulse responses in response to an unexpected one percent asset purchase announcement as a fraction of 2014 Q4 GDP, together with 68\% Bayesian credible sets. We show results for all four identification schemes for Portugal. 10,100 simulations, with the first 10,000 as burn-in, were used to generate the responses. The vertical axis is expressed in percent, while the horizon axis indicates the number of monthly time periods since the anouncement. 
Figure A6: Spanish impulse responses to a 1\% QE announcement shock
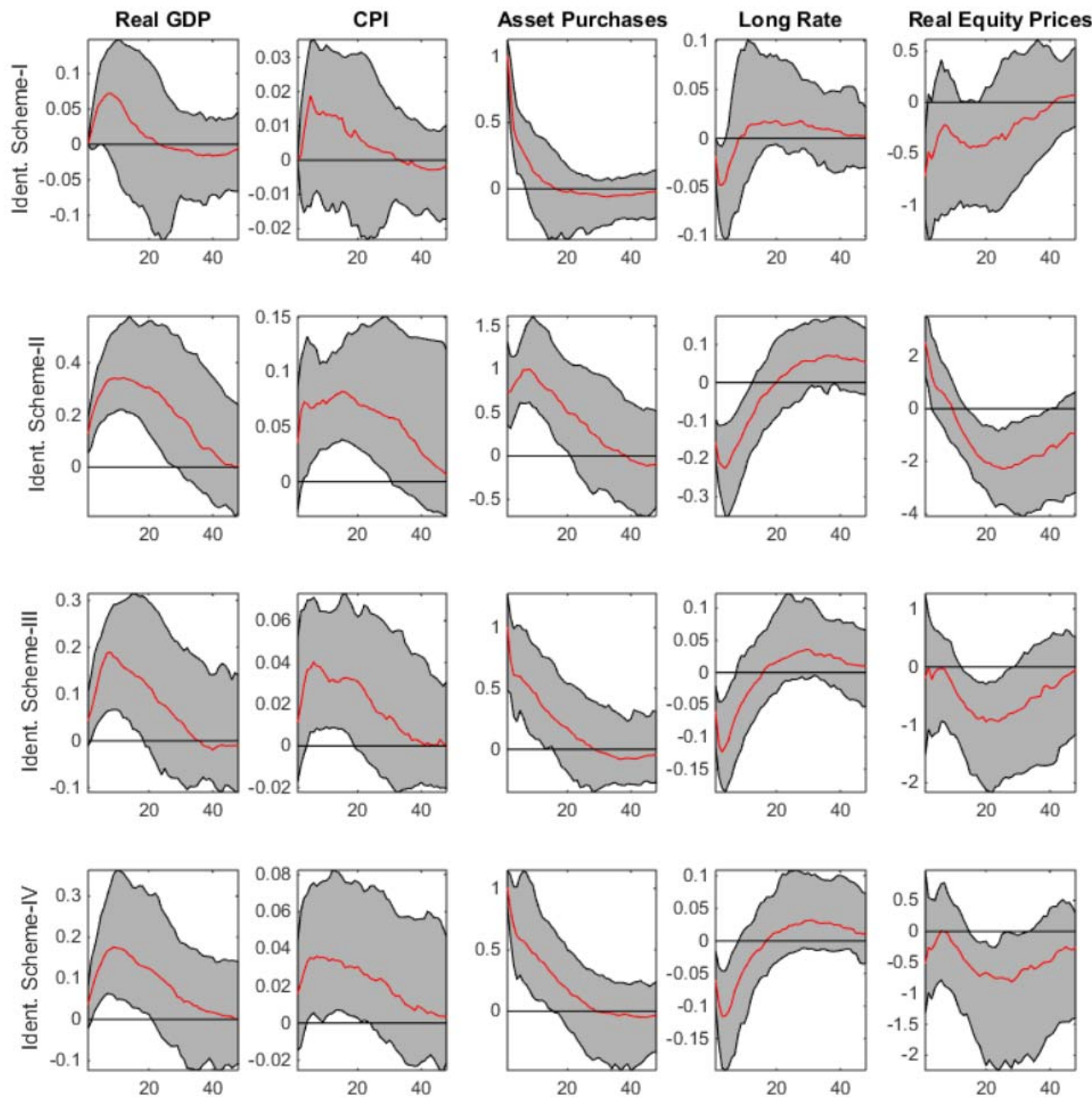

68th Quantile — Median

Note: This figure shows, for each of the variables in our model, the median impulse responses in response to an unexpected one percent asset purchase announcement as a fraction of 2014Q4 GDP, together with 68\% Bayesian credible sets. We show results for all four identification schemes for Spain. 10,100 simulations, with the first 10,000 as burn-in, were used to generate the responses. The vertical axis is expressed in percent, while the horizon axis indicates the number of monthly time periods since the anouncement. 